This item was submitted to Loughborough's Research Repository by the author.

Items in Figshare are protected by copyright, with all rights reserved, unless otherwise indicated.

\title{
A study on the effect of debris location on a double element wing in ground effect
}

PLEASE CITE THE PUBLISHED VERSION

https://doi.org/10.4271/2020-01-0693

PUBLISHER

SAE International

VERSION

AM (Accepted Manuscript)

\section{PUBLISHER STATEMENT}

This paper was accepted for publication in the journal SAE Technical Papers and the definitive published version is available at https://doi.org/10.4271/2020-01-0693

LICENCE

CC BY-NC-ND 4.0

\section{REPOSITORY RECORD}

Marsh, Tom, Graham Hodgson, Andrew Garmory, and Dipesh Patel. 2020. "A Study on the Effect of Debris Location on a Double Element Wing in Ground Effect”. figshare. https://hdl.handle.net/2134/12136056.v1. 


\title{
A Study on the Effect of Debris Location on a Double Element Wing in Ground Effect
}

\begin{abstract}
Multi-element front wings are essential in numerous motorsport series, such as Formula 1, for the generation of downforce and control of the onset flows to other surfaces and cooling systems. Rubber tyre debris from the soft compounds used in such series can become attached to the wing, reducing downforce, increasing drag and altering the wake characteristics of the wing. This work studies, through force balance and Particle Image Velocimetry (PIV) measurements, the effect a piece of debris has on an inverted double element wing in ground effect. The debris is modelled using a hard-setting putty and is located at different span and chord-wise positions around the wing. The sensitivity to location is studied and the effect on the wake analysed using PIV measurements. The largest effect on downforce was observed when the debris was located on the underside of the wing towards the endplates. The wake was most effected when the debris was located closest to the gap, generating a large fluctuating wake with a significantly different path to the baseline case.
\end{abstract}

\section{Introduction}

The aerodynamic performance of a vehicle can be characterised in terms of its downforce and drag. Improvements in these parameters are key for reducing lap times [1]. The maximum lateral and longitudinal forces developed through tyre adhesion are proportional to the vertical force at the contact patch. The addition of downforce therefore increases the maximum forces generated by the tyres, permitting increased cornering speeds, and improvements in braking and acceleration [2]. A reduction in drag increases the top speed on straights. Of equal importance to absolute downforce and drag is the balance and predictability of the car, which has implications for the driveability of the vehicle. A well balanced car will boost driver confidence and result in faster lap times $[3,4]$.

The front wing of a Formula 1 car generates approximately 25-30\% [3] of the total downforce of the vehicle. Modern Formula 1 front wings are very complex and are designed to operate in close proximity to the ground to exploit 'ground effect', where significantly greater forces and efficiency can be generated than in the freestream. An example of a modern Formula 1 front wing can be seen in Figure 1. The downforce is vital to the aerodynamic balance of the car; if the centre of pressure is too far forward then the car will tend to oversteer, too far back and it will understeer [6]. Additionally, the front wing conditions the flow for the other downforce generating surfaces, for cooling systems (e.g. brakes and power unit) and for control around the front tyres.

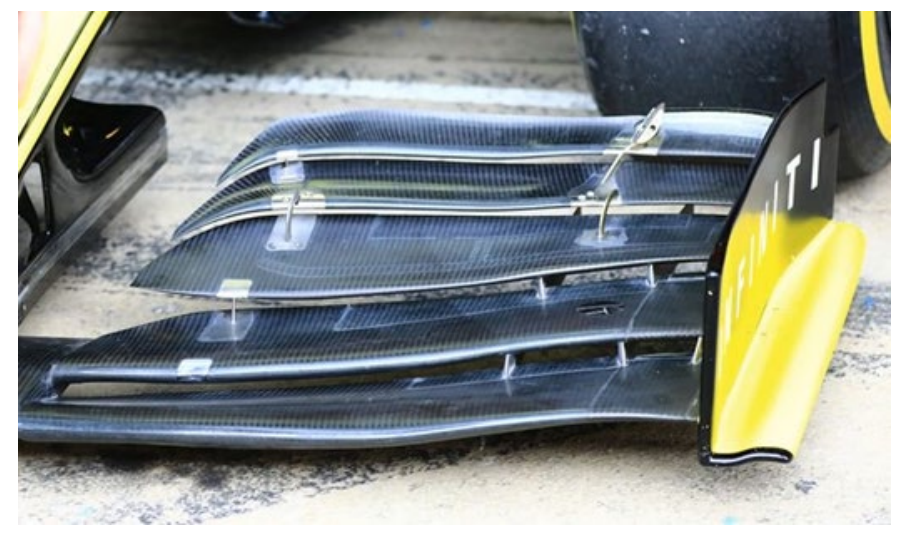

Figure 1. Renault RS19 front wing [5]

Throughout a race, the tyres degrade, and small pieces of rubber known as 'marbles' can be deposited on the track. This can easily be picked up by the front wing and could be detrimental to the performance of the entire vehicle. Figure 2 shows a front wing with evidence of such debris. This work aims to identify the areas on a wing that are most sensitive to debris and how this affects the aerodynamic performance of the wing and vehicle. Additionally, the effect on the downstream wake due to debris will be examined. This will be investigated through experimental testing, conducting parametric studies using discrete pieces of debris on a wing in the Loughborough University Large Wind Tunnel. The effects are also be put into context of the wider vehicle's performance. 


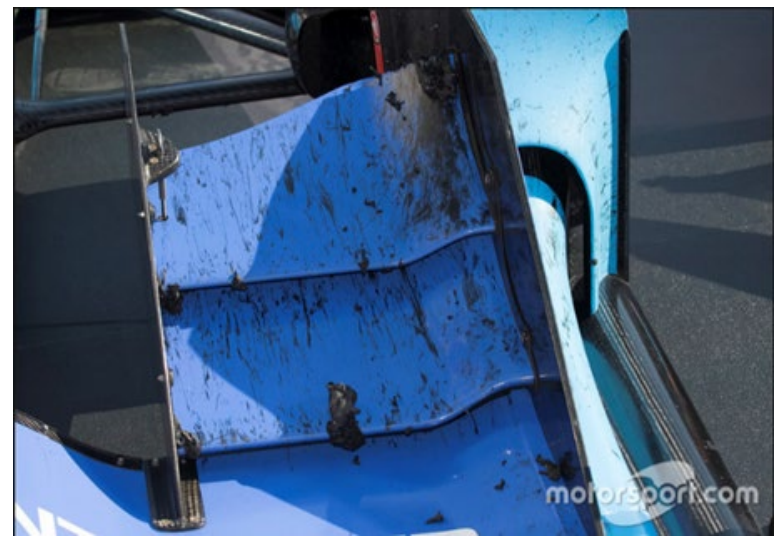

Figure 2. Front wing with evidence of tyre debris [7]

\section{Debris on Wings}

There is very little published work examining the effects of debris on wings in ground effect. Corfield [8] performed an experimental study of the effects of debris blocking the slot gap for an inverted double element wing in ground effect, using tape to model the debris. Although no moving ground plane facility was employed, a false floor was used to minimise the effects of the ground boundary layer. The debris results in a loss of downforce, since the slot-gap blockage causes the flow to separate on the suction side of the flap, reducing overall wing loading. Span-wise variations in the flap gap were also observed, due to the three-dimensional flow [9]. Drag decreased compared to the clean case, as a result of the decreased induced drag, highlighting the significant induced drag contribution for low aspect ratio wings. Comparison over two ground clearances revealed that debris was more detrimental the more highly loaded the wing is. Additionally, the wing caused significant flow separation on the false floor, which is unrealistic compared to real world conditions and introduces errors.

Whilst ice accretion is not a typical feature on a race car front wing during a race, its effects are similar to those due to the presence of debris. By investigating the effects of three ice shape variants at six different chordwise locations biased towards the leading-edge, Kim [10] was able to offer an insight into the effects of ice accretion on an aerofoil. In the instance that the ice accreted directly upon the leading-edge of the aerofoil, the effect of the shape of the ice was minimal although drag was observed to increase, being more pronounced at relatively large angles of attack. By locating the ice further downstream from the leading-edge, the effects of the ice shape affected particularly the aerofoil's lift, which reduced, and the angle of attack at which stall occurred decreased as the vertical length of the ice increased. Ultimately, lift and drag were decreased and increased respectively relative to an aerofoil without the accretion of ice; similar findings were also noted by Pouryoussefi [11] who stated that the upstream movement of flow separation from the trailing-edge and the formation of a separation bubble behind the ice formation was responsible for the effects observed.

\section{Experimental Methodology}

\section{Model}

The wing geometry is shown in Figure 3. The wing is a two-element inverted wing, mounted to two L-shaped endplates and is approximately $50 \%$ scale by chord compared to a modern Formula 1 wing. The mainplane is a NACA4412 section of 200 mm chord, angled at an incidence of 1 degree upwards. The flap has a chord length of $79 \mathrm{~mm}$ with a custom aerofoil cross-section, set at an angle of 22 degrees with a gap of $0.033 c$ (9 mm) and an overlap of $0.026 c(7 \mathrm{~mm})$ to the mainplane, giving a combined reference chord length of $272 \mathrm{~mm}$ resulting in $b / c=1.838$. Thin wind tunnel tape was used to cover the holes in the endplate, preventing any jetting effects. Details of the wing design process can be found in Corfield et al. [8]. The origin is defined at the centre line of the span, at the most upstream location on the wing (shown in Figure 3 ). The ride height was set to $h / c=$ 0.42 to ensure no separation occurred on the floor, while maximising ground effect.
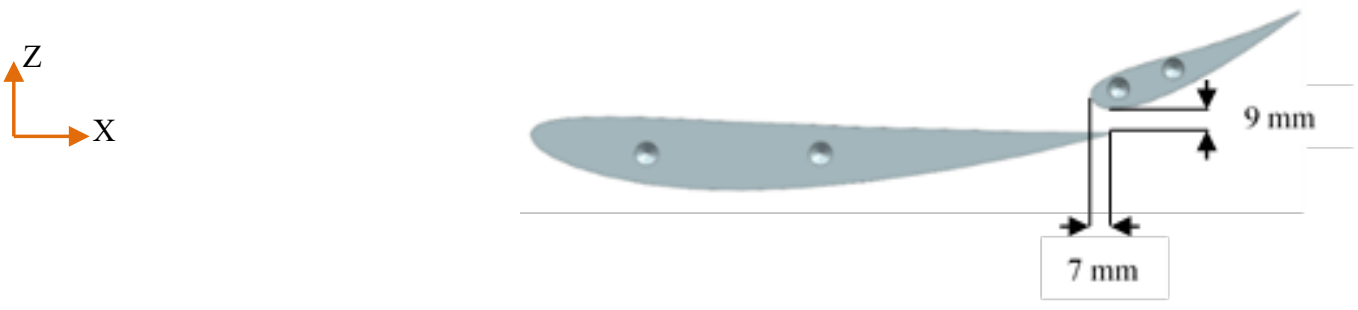

Figure 3. Model wing geometry including axis orientation

Page 2 of 14

$01 / 14 / 2020$ 
Debris was modelled in the wind tunnel using Loctite 'kintsuglue' putty. This is an easily mouldable, self-hardening material. The putty was moulded into hemispheres of varying diameter. To ensure adhesion to the wing and to prevent the putty from damaging the wing surface, the putty was bonded to thin wind tunnel tape using superglue and stuck firmly to the wing. Figure 4 shows an example of a test arrangement looking from the contraction downstream towards the wing. The debris can be seen on right hand side of the pressure surface in the slot gap.

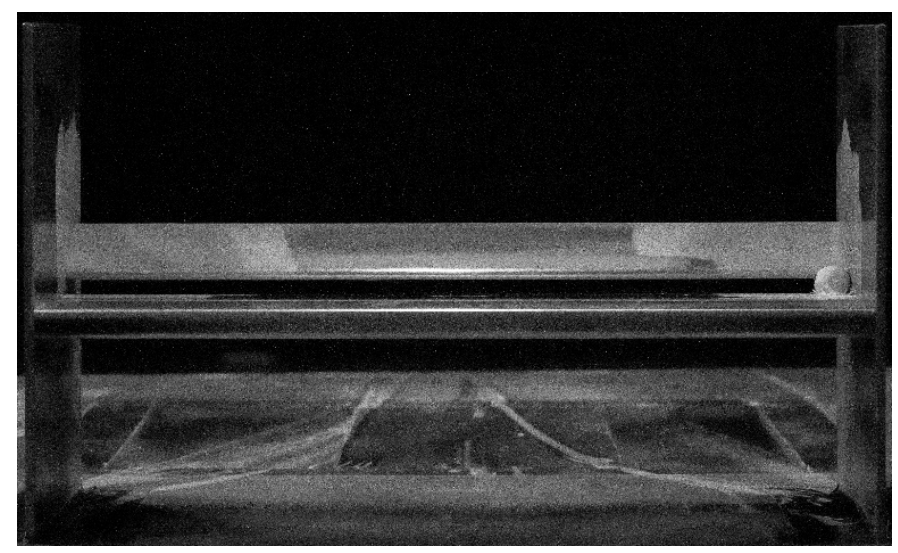

Figure 4. Image showing wing and debris (located in maximum y position at $y / c=0.5$ and $x / c=0.739$ ) looking downstream

Debris location was measured from the leading edge of the wing to the leading edge of the debris chordwise, whilst span location was measured from wing centre line to the centre line of the debris. These are shown schematically in Figure 5. Debris size is non-dimensionalised by normalising the diameter by wing chord length.

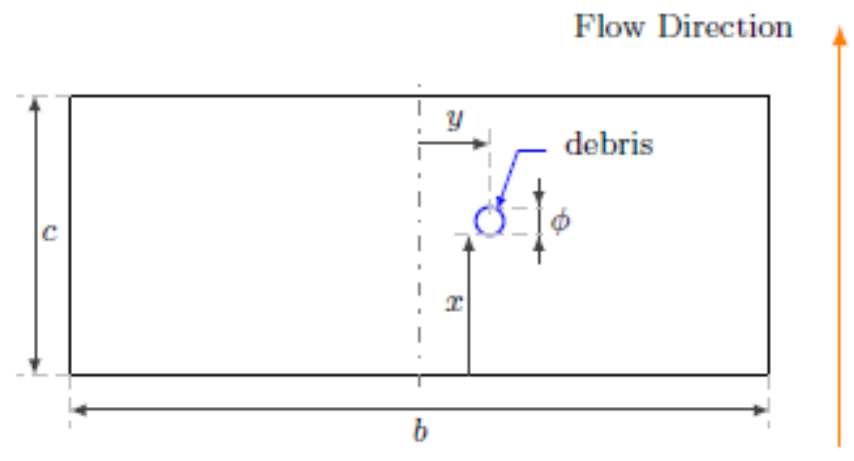

Figure 5. Schematic showing the location variables

\section{Tunnel and PIV}

The investigation was conducted using the Loughborough University Large Wind Tunnel, with full details available in Johl et al. [12]. The tunnel is an open loop indraft style, with working section dimensions of 1920 x $1320 \mathrm{~mm}$, diverging to $1940 \times 1320 \mathrm{~mm}$ over $3600 \mathrm{~mm}$. The tunnel features divergence on the side walls of the working section to account for the increase in boundary layer thickness along the tunnel walls, minimising horizontal buoyancy effects that can influence the drag measurements $[12,13]$. The turbulence intensity at the centre of the working section is measured to be $0.15 \%$ at $40 \mathrm{~m} / \mathrm{s}$, with a velocity uniformity of $\pm 0.1 \%$ in the floor region.

The tunnel is not equipped with a moving ground plane and therefore the development of a ground boundary layer on the tunnel floor must be considered. A ground boundary layer is not present in real world conditions and can affect the results [14]. The boundary layer creates a small blockage, reducing the effective ground clearance beneath the wing, increasing the forces generated. In contrast, at very low ground clearances the boundary layer is influenced by the pressure gradients around the wing, causing it to merge with the wing or separate from the floor completely.

To minimise these effects, a false floor was employed. The false floor extended $1170 \mathrm{~mm}$ upstream of the wing model. At the testing velocity of $40 \mathrm{~m} / \mathrm{s}$, the boundary layer on the false floor is assumed to be turbulent, and a displacement thickness according to the $1 / 7$ th power law has been calculated using Equation 1.

$$
\frac{\delta^{*}}{x}=\frac{0.046}{\left(\operatorname{Re}_{\mathrm{x}}\right)^{0.2}}
$$

Page 3 of 14

$01 / 14 / 2020$ 
The displacement thickness was calculated as $2.8 \mathrm{~mm}$, corresponding to $2 \%$ of the $115 \mathrm{~mm}$ ground clearance, which should have negligible influence on the results. The blockage ratio of the model setup in the tunnel was calculated as $2.7 \%$.

According to the 2019 FIA technical regulations, the maximum allowable front wing chord length is $575 \mathrm{~mm}$ [15]. The mean speed for a Formula 1 car has been calculated by averaging the fastest lap for the first 5 circuits in the 2019 season, giving $59 \mathrm{~m} / \mathrm{s}$ [16], corresponding to a chord-based Reynolds number of $2.23 \times 10^{6}$. The Loughborough University Large Wind Tunnel is limited to $40 \mathrm{~m} / \mathrm{s}$ and so it is not possible to match Reynolds number (Equation 2) for dynamic similarity. For the $50 \%$ model at a velocity of $40 \mathrm{~m} / \mathrm{s}$, the chord-based Reynolds number is $7.3 \times 10^{5}$.

$$
\operatorname{Re}=\frac{\rho U L}{\mu}
$$

Forces were recorded using a 6-component force balance situated below the tunnel and connected via a series of pins in the floor to transmit the loads from the endplates to the balance. Instantaneous force measurements were recorded at $300 \mathrm{~Hz}$, sampling for a total of 300 seconds and averaged over this sampling period. During each test point, once the tunnel speed was set, the model was allowed to settle for 20 seconds before sampling began. A yaw angle sweep was conducted during the initial setup on the wing in isolation to find the zero-yaw angle, where side force is zero. The reference velocity is recorded $2 \mathrm{~m}$ upstream of the model at a height of $1.12 \mathrm{~m}$ with a $0.5 \mathrm{~m}$ lateral offset.

Table 1. Range and accuracy of force measurements from the under-floor balance

\begin{tabular}{lcc}
\hline Component & Force Range (N) & $\begin{array}{l}\text { Accuracy (\% of full } \\
\text { scale) }\end{array}$ \\
\hline Drag, $C_{D}$ & \pm 120 & 0.010 \\
Side Force, $C_{y}$ & \pm 420 & 0.005 \\
Lift, $C_{L}$ & \pm 500 & 0.010
\end{tabular}

PIV was used throughout the experiment to measure the wake profile of the wing, with the arrangement shown schematically in Figure 6 . The flow was seeded using small tracer DEHS (Di-Ethyl-Hexyl-Sebacat) particles, of 1 micron diameter, that are considered to follow the flow field faithfully [17]. These were emitted from a rake located at the start of the contraction and from a boundary layer seeder located at the start of the working section. A Nd-YAG $200 \mathrm{~mJ}$ laser was directed through a series of lenses and mirrors to generate a vertical streamwise light sheet at Y=0 (wing centerline), illuminating the flow field and scattering off the tracer particles. A high-speed LaVision sCMOS camera was used to capture 1000 image pairs, being sufficient to ensure statistical convergence to the mean flow field [18]. A correlation based post-processing software calculates the velocity profile of the flow field by reconstructing the movement of the particles between the sequential image pair. For accuracy, the time steps should be small, in order that local particle trajectories are approximately straight. Time step selection is a trade-off between resolution of low and high velocity regions. Small time steps are required to capture high velocity flows, but resolution is lost in lower velocity regions [19]. A 'dt' time step sweep was initially conducted to find the optimum time step. For a velocity of $40 \mathrm{~m} / \mathrm{s}$ the time step between images was chosen as 45 micro-seconds. For measurement of the mean flow field, image pairs were sampled at $15 \mathrm{~Hz}$. The measurement plane was $450 \mathrm{~mm}$ width $\mathrm{x}$ $300 \mathrm{~mm}$ height downstream of the trailing edge and on the wing's centre line. 


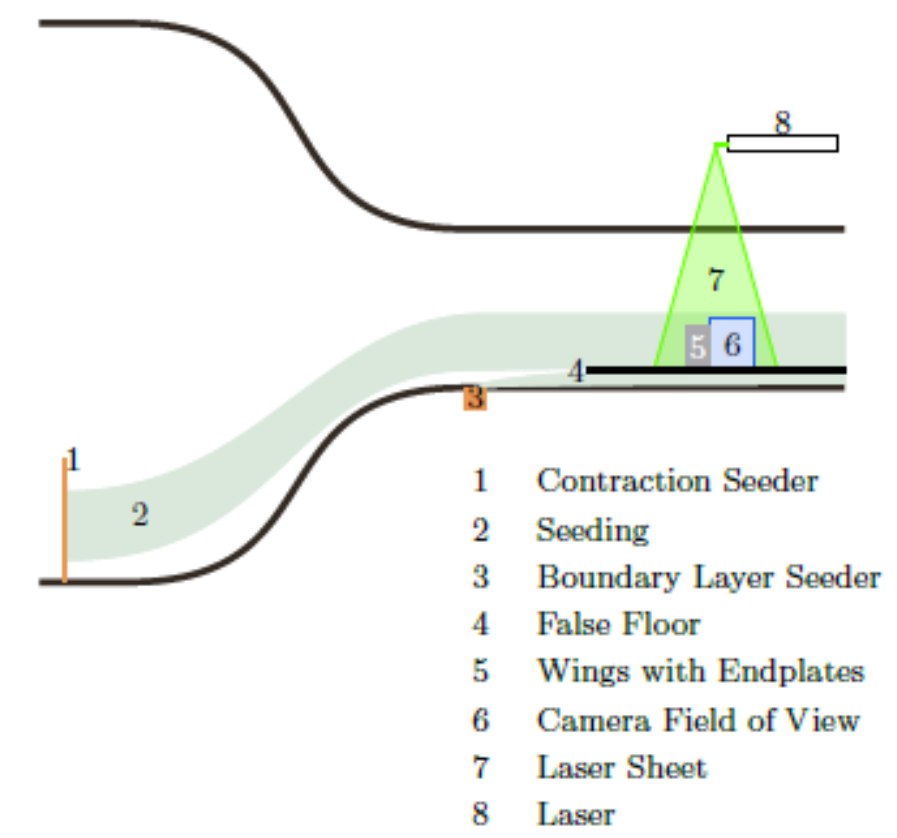

Figure 6. Schematic showing the experimental arrangement for the PIV tests

\section{Results}

\section{Reynolds Sensitivity}

A Reynolds number sweep was conducted with the wing in its clean configuration. This was conducted with velocities ranging from 20 to $40 \mathrm{~m} / \mathrm{s}$, in increments of $5 \mathrm{~m} / \mathrm{s}$. The lift and drag coefficients are calculated using Equations 3 and 4, where area, $\mathrm{S}$, is the planform area of the wing, defined as the span multiplied by the combined mainplane and flap chord length.

$$
\begin{aligned}
C_{L} & =\frac{L}{0.5 \rho U^{2} S} \\
C_{D} & =\frac{D}{0.5 \rho U^{2} S}
\end{aligned}
$$

The lift coefficient increases slightly (note the scales) with Reynolds number and drag coefficient reduces with increasing Reynolds number (shown in Figure 7), agreeing with observations by Zerihan and Zhang [9].

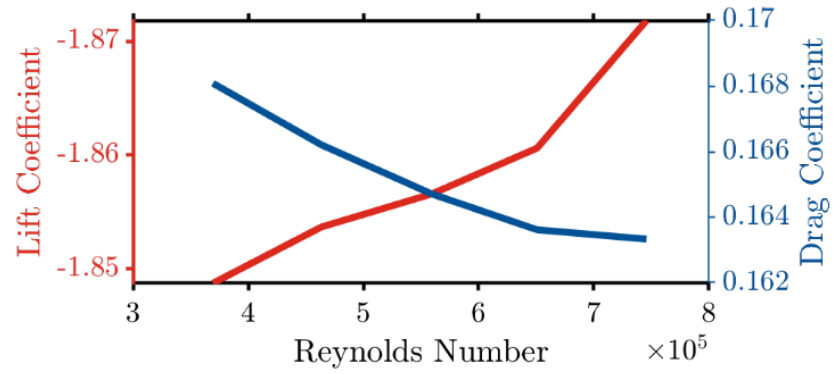

Figure 7. Experimental lift and drag coefficients of the clean wing with varying Reynolds Number

\section{Debris Size}

There is no published data on the average size of marbles that build up on a track. Therefore, a range of sizes have been tested, all of a similar size to the slot-gap, ranging from $\varnothing / \mathrm{c}=0.036-0.110(10$ to $30 \mathrm{~mm})$ in diameter. A size sweep was performed at a fixed location on the wings upper surface, at mid-span and at $10 \%$ of the mainplane chord, or $7.3 \%$ of the combined wing chord. The velocity was also varied for each debris size to observe any changes with Reynolds number. Figure 8 and Figure 9 show the lift and drag coefficients respectively.

Page 5 of 14

$01 / 14 / 2020$ 


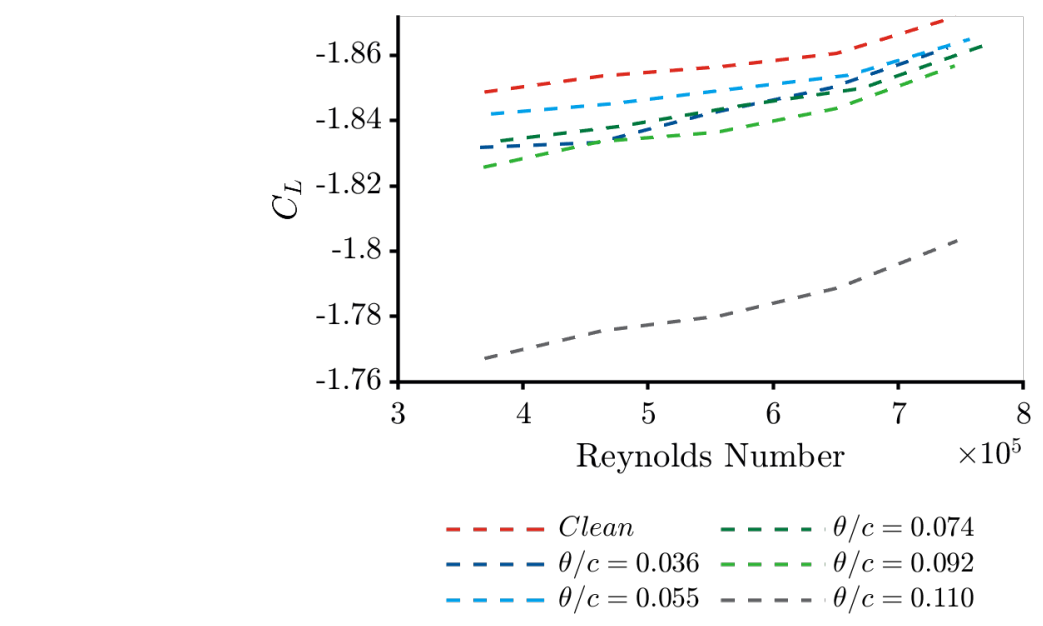

Figure 8. Lift coefficient as a function of Reynolds numbers for varying non-dimensional debris size

It is observed that the addition of debris results in a loss of downforce compared with the clean wing, generated as a result of the interaction with the downstream flap. There is a general trend that the greater the diameter of the debris, the greater the loss of downforce. However, there is a small discrepancy for the debris of size 0.036 , which has a greater loss of downforce than for the debris of size 0.055 . This could be due to an anomaly in the shape or location of debris on the wing. There is a large drop off in downforce between the debris size of 0.092 and $0.11 \varnothing / \mathrm{c}$.

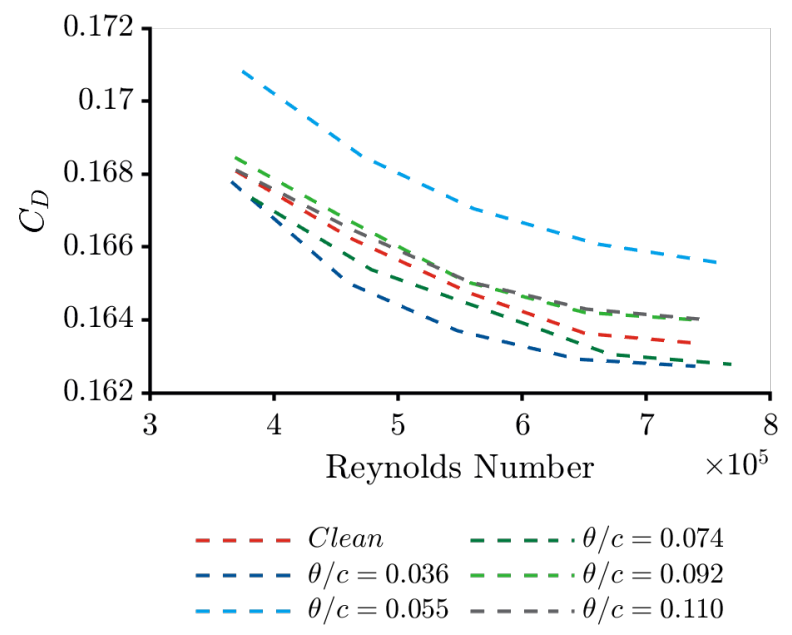

Figure 9. Drag coefficient as a function of Reynolds numbers for varying non-dimensional debris size

The drag coefficient is also dependent on debris size and appears to be split into two regimes; smaller diameter debris resulted in a drag reduction, since the loss of loading reduces induced drag, whilst the larger debris from $0.092-0.11 \varnothing / \mathrm{c}$ resulted in a drag increase. This is thought to be due to a large-scale separation causing greater pressure drag. Debris of this size is much less likely, being approximately 25-30 mm in diameter.

The debris has little effect on the Reynolds sensitivity of the wing. The different sizes yield similar gradients and trends with a static offset between them.

\section{Location Sweeps}

A debris location sweep was performed on the wings pressure and suction surfaces using a constant size of $0.0735 \varnothing / \mathrm{c}$ to allow comparison and determine the locations most sensitive to debris. Figure 10 to Figure 13 compare the percentage change in lift and drag coefficients compared with the clean wing for varying debris location, with Figure 10 and Figure 11 being the lift and drag co-efficient for the pressure surface respectively, Figure 12 and Figure 13 being the same for the suction surface. The leading edge of the flap is denoted by the dashed line. Note that a positive $\Delta C_{L}$ is a loss of downforce.

Figure 10 reveals that on the pressure surface, the loss of downforce is more detrimental further along the chord of the mainplane and further from the wing's centre line, with the most detrimental location in front of the flap near to the endplates, with a $2.6 \%$ loss of downforce. This is a result of either or both the flap stalling in this location or an effect on a vortical structure. Debris on the flap's trailing edge creates a small increase in downforce, likely a result of an increase in pressure similar to that observed with the addition of Gurney Flaps [20].

Page 6 of 14

$01 / 14 / 2020$ 
Figure 11 shows the debris on the centre line of the mainplane across the whole chord results in a drag reduction. Debris closer to the wing tips, increases drag, especially as it approaches the slot gap. Debris positioned on the flap trailing edge generates the largest drag increase, being similar in magnitude across the span.

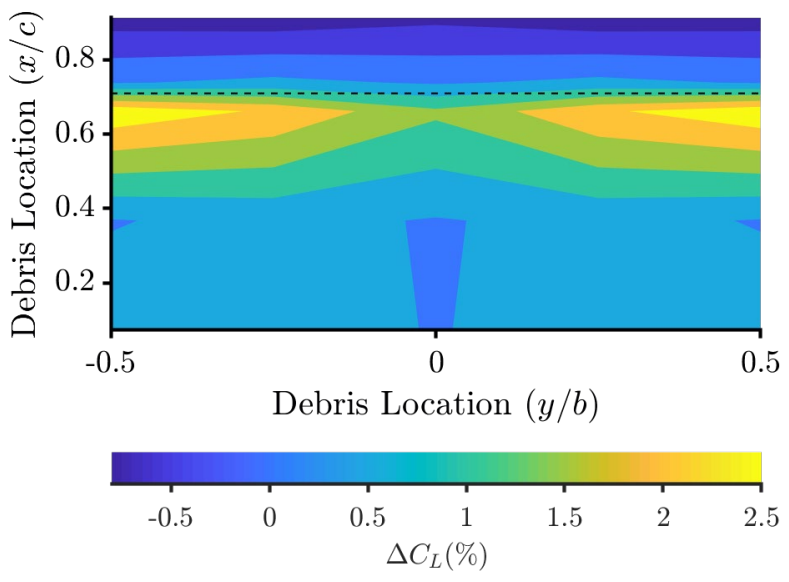

Figure 10. Pressure surface $\Delta C_{L}$ compared with clean wing for varying debris location

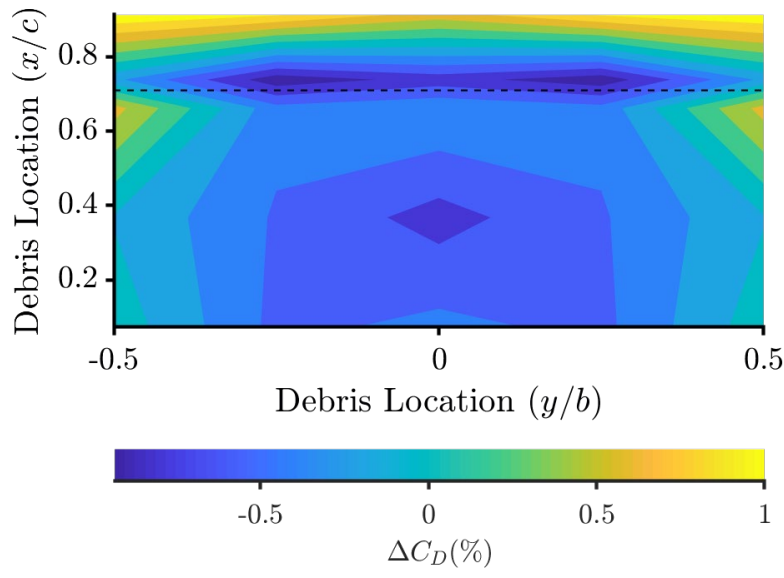

Figure 11. Pressure surface $\Delta C_{D}$ compared with clean wing for varying debris location

Figure 12 and Figure 13 show that debris creates a much greater change in performance on the suction surface, since it is much more highly loaded. The greatest loss of downforce occurred at the wing tips at approximately mid-chord of the mainplane, with an $11 \%$ change in lift coefficient.

Equally, the drag also increased the most at this location, with a 7\% increase in drag coefficient. Debris on the suction surface of the flap resulted in a reduction in drag by $1 \%$. It is inferred that debris is of greatest detriment to lift and drag when it is incident on the most loaded regions of the wing.

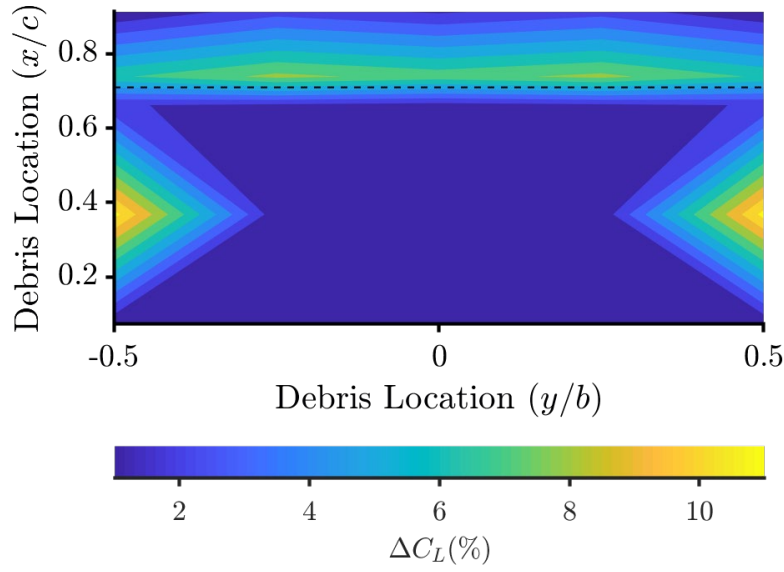

Figure 12. Suction surface $\Delta C_{L}$ compared with clean wing for varying debris location

Page 7 of 14

$01 / 14 / 2020$ 


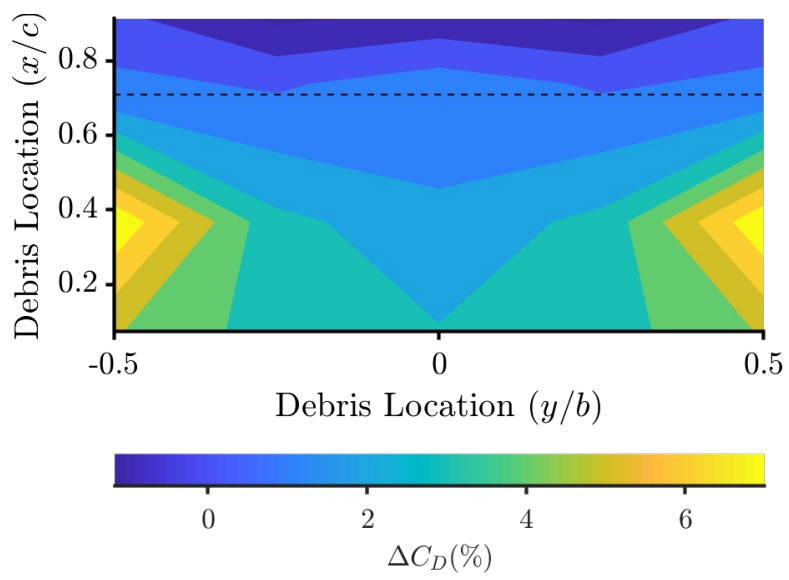

Figure 13. Suction surface $\Delta C_{D}$ compared with clean wing for varying debris location

\section{Wake Analysis}

The PIV system was used to observe the mean and fluctuating wake profiles of the wing at midspan. Velocities are normalised by the mean freestream velocity of $40 \mathrm{~m} / \mathrm{s}$. Table 2 shows the lift and drag co-efficients for the locations of interest.

\section{Table 2. Lift and drag coefficients for the cases investigated with PIV planes}

\begin{tabular}{lcc}
\hline Debris & $\boldsymbol{C}_{\boldsymbol{L}}$ & $\boldsymbol{C}_{\boldsymbol{D}}$ \\
\hline Clean & -1.872 & 0.163 \\
Suction Side & -1.853 & 0.167 \\
Pressure Side & -1.863 & 0.162 \\
Slot & -1.730 & 0.166 \\
\hline
\end{tabular}

Figure 14 shows the mean wake for the clean wing. Clearly visible are the two distinct velocity minima formed from the mainplane and flap, with the mainplane the thicker of the two wakes, as observed in [21]. Also evident is the upwash produced behind the wing.

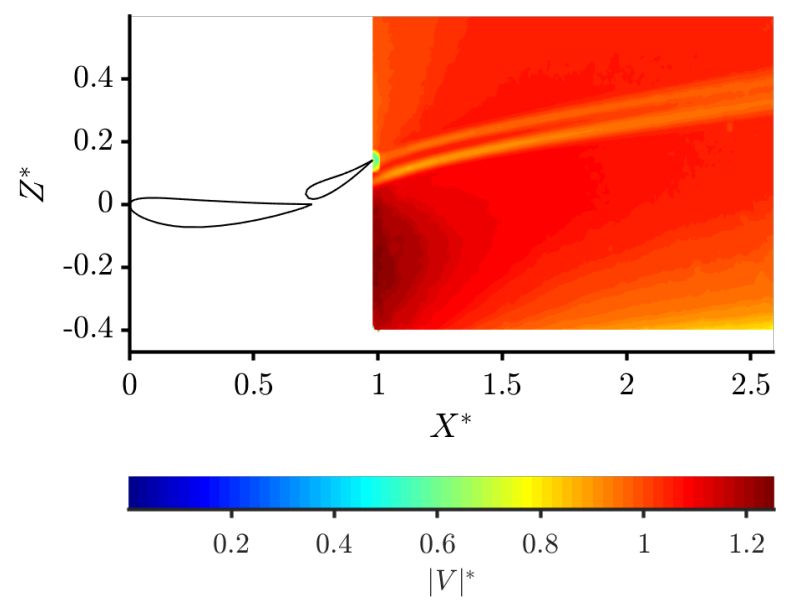

Figure 14. Mean normalised velocity flow field of a clean wing at $Y^{*}=0$

Figure 15 shows the wake with debris applied on the suction surface and mid-chord of the mainplane. The wake shed from the mainplane thickens, due to boundary layer thickening and separation, caused by the interference of the debris, but there is no effect on the flap wake. The wakes subsequently merge half a chord-length downstream. The location of the main wing wake implies that the flow has successfully reattached on the suction side, which results in only a slight increase in drag.

\section{Page 8 of 14}




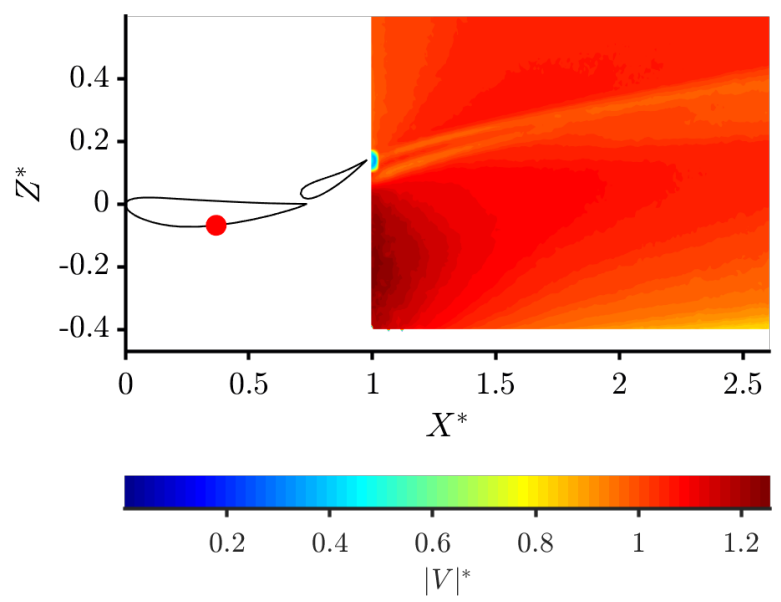

Figure 15. Mean normalized velocity flow field of a wing with debris located at $x / c=0.36$ on the suction surface and theta/c=0.0735 and $Y^{*}=0$

Figure 16 shows the difference in the flowfield when compared to the clean state, with blue indicating where the debris flowfield is slower than the clean one and the red indicating where it is faster. It can be seen that the flowfields are virtually the same for a significant region. The wakes have a lower upwash, correlating with the near twenty count reduction in downforce observed.

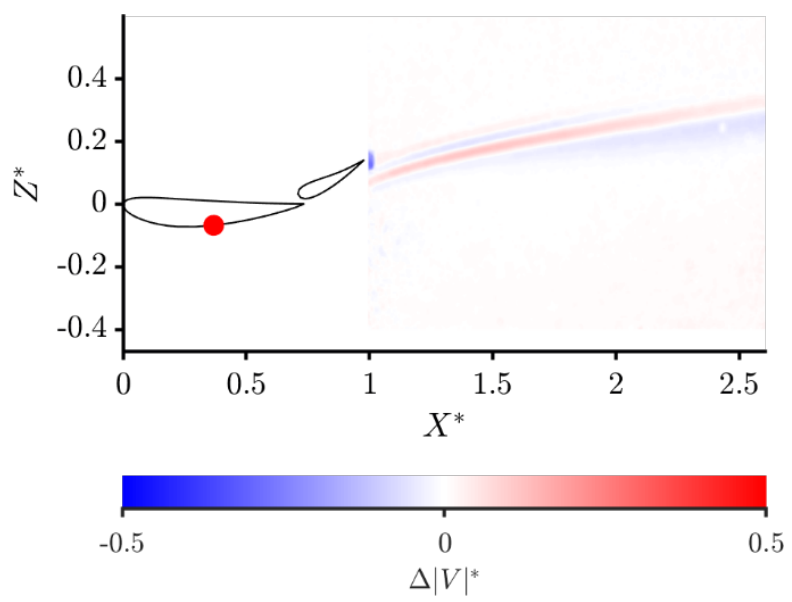

Figure 16. Difference between normalised velocity flow field with debris located at $x / c=0.36$ on the suction surface and theta/c $=0.0735$ against clean wing at $Y^{*}=0$

In contrast, with the debris on the same location on the pressure surface of the mainplane as in Figure 17, the effect on the wake is much more severe. The debris generates a low energy turbulent wake, which passes through the slot gap, and results in the flow separating from the flap trailing edge, as signified by a low velocity at the trailing edge. 


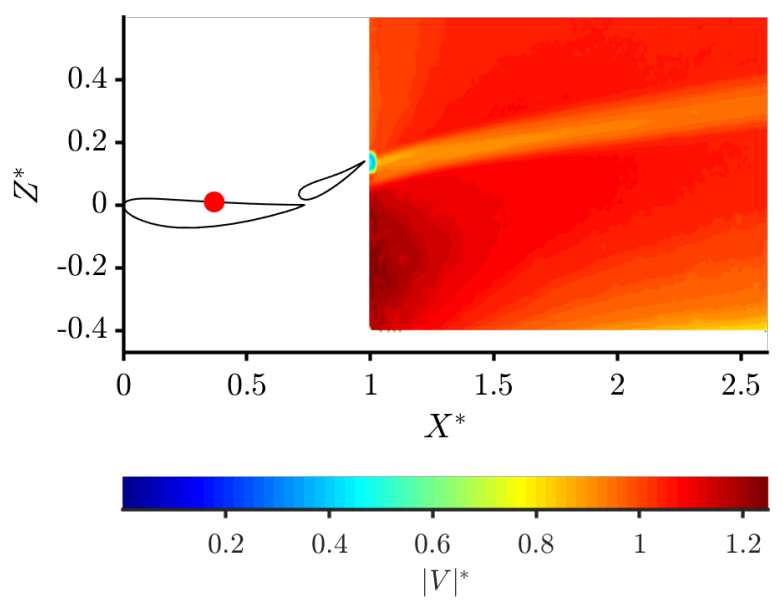

Figure 17. Mean velocity flow field of a wing with debris located at $x / c=0.36$ on the pressure surface and theta/c=0.0735 and $Y^{*}=0$

Figure 18 again shows the different in the flowfield when compared to the clean state. Both the size and magnitude of the regions of difference have increased and the pattern follows a similar trend in demonstrating a reduction in upwash.

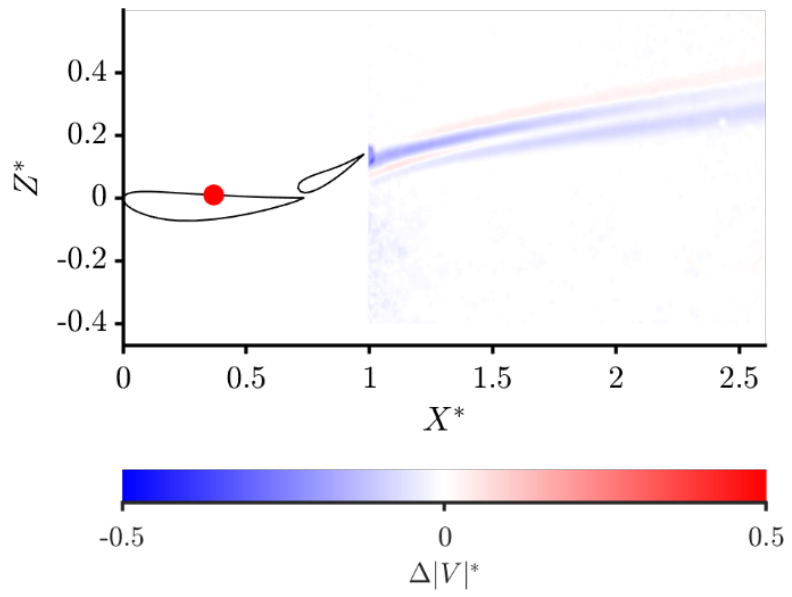

Figure 18. Difference between normalised velocity flow field with debris located at $x / c=0.36$ on the pressure surface and theta/c=0.0735 against clean wing at $Y^{*}=0$

Figure 19 reveals the wake with debris in the slot gap. The debris induces flow separation along the suction side of the flap, as can be seen from the large region of low velocity flow extending downstream. There is almost no upwash, inferring a significant loss of wing loading in this plane.

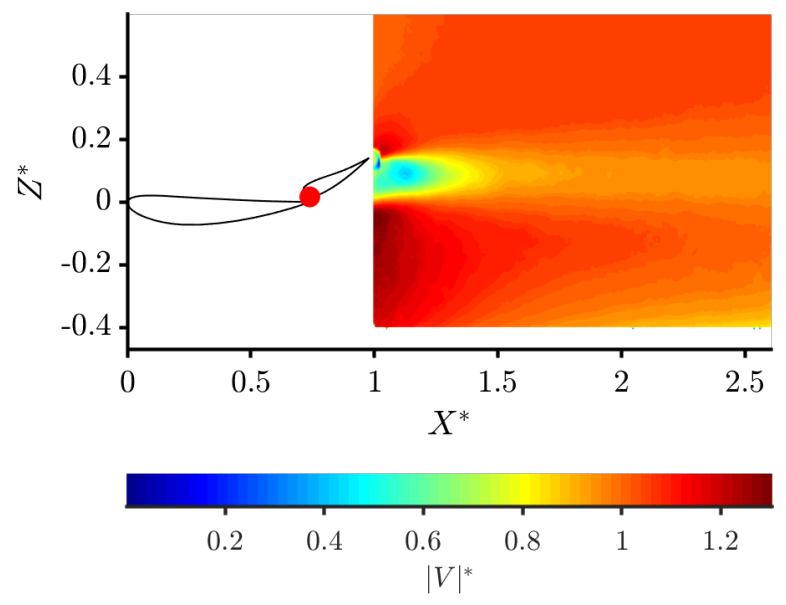

Figure 19. Mean velocity flow field of a wing with debris located at $x / c=0.74$ on the suction surface and theta/c=0.0735 and $Y^{*}=0$

Page 10 of 14

$01 / 14 / 2020$ 
Figure 20 shows the RMS of the flowfield for the debris in the slot case. The wake is highly unsteady immediately behind the flap and continues downstream. Given the geometries, it is implied that vortices are being shed from the flap and are propagating downstream. Figure 21 shows the difference in the mean flowfield compared to the clean state, with the expected significant differences.

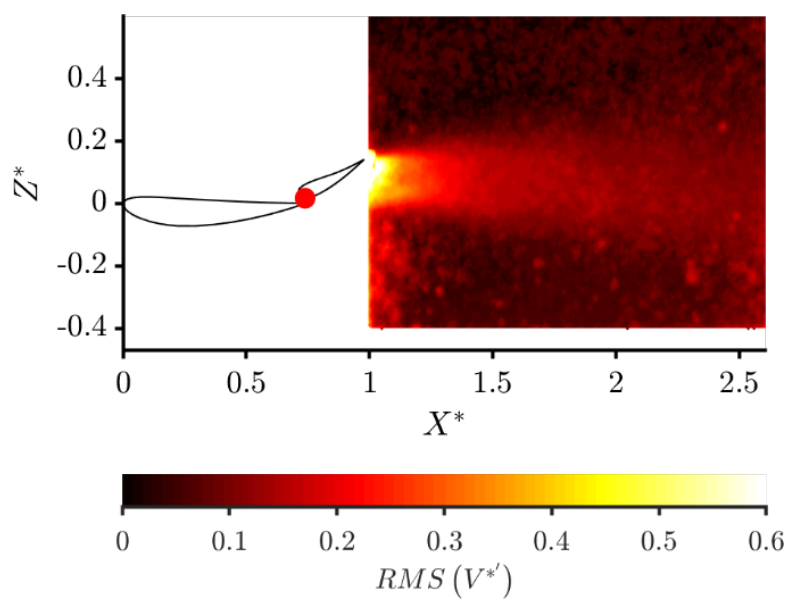

Figure 20. RMS of the normalized velocity flow field with debris located at $x / c=0.74$ on the suction surface and theta/c=0.0735 at $Y^{*}=0$

From these results, it appears that pressure surface debris has a much greater influence on the wake and debris on the suction surface having a less pronounced effect. The closer the debris is to the slot gap, the more severe the wake.

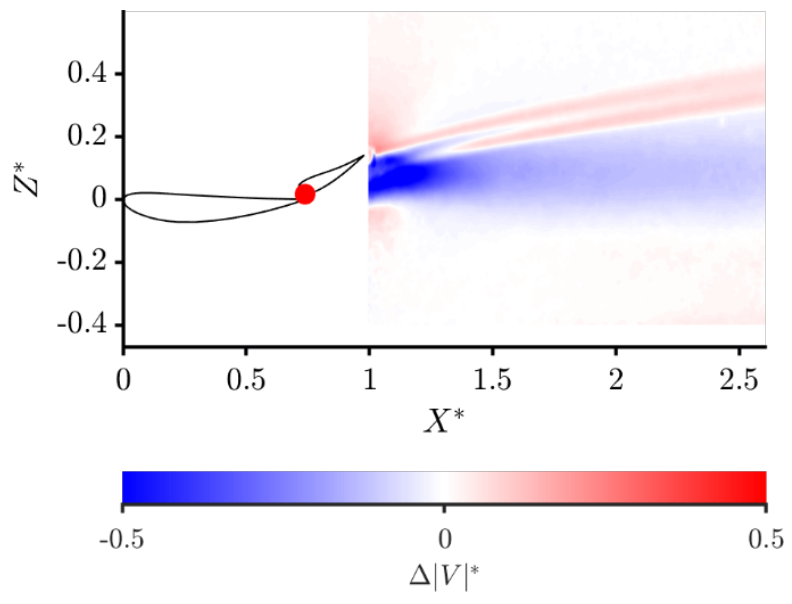

Figure 21. Difference between normalised velocity flow field with debris located at $x / c=0.74$ on the suction surface and theta/c $=0.0735$ against clean wing at $Y^{*}=0$

\section{Conclusions}

The effects of varying debris sizes have been examined. The larger the diameter of the debris, the greater the loss of downforce. The change in drag is size specific, with smaller pieces creating a drag reduction due to a loss of wing loading reducing induced drag. In contrast, larger pieces resulted in a drag increase, caused by large amounts of flow separation increasing pressure drag.

The results showed Reynolds number dependency, producing a more severe effect at lower speeds. The larger debris sizes also showed greater Reynolds number sensitivity compared with smaller sizes of debris.

The effects were found to vary with both spanwise and chordwise location. On the upper surface, the most detrimental location is in front of the flap gap, near the wing tips, where a strong interaction occurs. On the lower surface, the most detrimental location is at mid-chord of the mainplane and near the tips, where loading was found to be greatest, due to the interaction with the tip vortices and was the most detrimental location of all. Debris on the trailing edge of the flap was found to increase downforce, as it behaves in a similar manner to a gurney flap.

The wake was also investigated using PIV. This revealed a thickening of the wake as a result of debris. Debris on the mainplane's upper surface had a greater effect on the wake, causing a low momentum wake to pass through the slot gap. A loss of upwash was also observed, signifying the loss of wing loading. Debris positioned close to the slot gap was seen to produce a severe wake profile, causing separation on the underside of the flap. The Page 11 of 14

$01 / 14 / 2020$ 
RMS of the flowfield revealed a large fluctuating component, suggesting the presence of a flapping motion indicative of vortex shedding. The change in the wake location and patterns were clearly observed when studying the difference to the clean state. When the debris was located on the pressure side the drag and lift co-efficients were very similar to the clean state but the location and magnitude of the wakes was clearly observed to have changed. Should these wakes be used to condition flow for downstream cooling or downforce generation then the impact on the overall aerodynamics would be magnified beyond those observed. Further work should endeavour to study the flowfield in three dimensions [22] to yield a greater understanding of the impact that debris has on the wake.

\section{References}

1. D. Jeffrey and M. Alperin, “Aspects of the aerodynamics of year 2000 Formula One racing cars," Mira Int. Veh. Aerodyn. Conf., no. October 2000, 2000.

2. Agathangelou, B. and Gascoyne, M., "Aerodynamic Design Considerations of a Formula 1 Racing Car," SAE Technical Paper 980399, 1998, https://doi.org/10.4271/980399

3. X. Zhang, W. Toet, and J. Zerihan, "Ground Effect Aerodynamics of Race Cars," Appl. Mech. Rev., vol. 59, no. 1, p. $33,2006$.

4. Dominy, R. G., "Aerodynamics of Grand Prix Cars," Proceedings of the Institution of Mechanical Engineers, Part D: Journal of Automobile Engineering 206, no. 44 (1992): 267-274, doi:10.1243/PIME_PROC_1992_206_187_02.

5. J. Samodien, “The Renault RS19 Front Wing”. https://twitter.com/JunaidSamodien_/status/1101427773409644544

6. Katz, J., Race Car Aerodynamics - Designing for Speed, Bentley Publishing, 2006.

7. Geoffrey M. Miller, "Scott Dixon, Chip Ganassi Racing Honda marbles on wings in parc ferme". Motorsport.com

8. Corfield, E., Hodgson, G., and Garmory, A., "A Computational and Experimental Investigation into the Effects of Debris on an Inverted Double Wing in Ground Effect," SAE Technical Paper 2018-01-0726, 2018, https://doi.org/10.4271/2018-01-0726.

9. Zerihan, J. and Zhang, X., “Aerodynamics of a Single Element Wing in Ground Effect,” Journal of Aircraft 37, no. 6 (2000):1058-1064, doi: $10.2514 / 2.2711$.

10. H.S. Kim and M.B. Bragg, "Effects of Leading-Edge Ice Accretion Geometry on Airfoil Performance", American Institute of Aeronautics and Astronautics, AIAA-99-3150, 1999.

11. S.G. Pouryoussefi, M. Mirzaei, M. Nazemi, M. Fouladi and A. Doostmahmoudi, "Experimental study of ice accretion effects on aerodynamic performance of an NACA 23012 airfoil", pp. 585-595, Chinese Journal of Aeronautics, Vol. 29, Issue 3, 2016.

12. Johl, G., Passmore, M., \& Render, P. "Design methodology and performance of an indraft wind tunnel”, The Aeronautical Journal, 108:1087, 2004.

13. D. Wood, M. A. Passmore, and A.-K. Perry, "Experimental Data for the Validation of Numerical Methods - SAE Reference Notchback Model," SAE Int. J. Passeng. Cars - Mech. Syst., vol. 7, no. 1, pp. 2014-01-0590, 2014.

14. D. W. Marshall, S. J. Newman, and C. B. Williams, "Boundary layer effects on a wing in ground-effect," Aircr. Eng. Aerosp. Technol., vol. 82, no. 2, pp. 99-106, 2010.

15. Fédération Internationale de l'Automobile, “2019 Formula One Technical Regulations,” FIA Tech. Regul., no. 29 April 2016 , p. $50,2018$.

16. Formula 1, "Formula 1 Race Results," 2019. [Online]. Available: https://www.formula1.com/en/results.html/2019/races/1000/australia/fastestlaps.html. [Accessed: 22-May-2019].

17. Melling, A., "Tracer particles and seeding for particle image velocimetry", 1997, Meas. Sci. Technol, 81406.

18. Passmore, M., Spencer, A., Wood, D., Jowsey, L. et al., "The Application of Particle Image Velocimetry in Automotive Aerodynamics.," SAE Technical Paper 2010-01-0120, 2010, doi: 10.4271/2010-01-0120.

19. S. Discetti and A. Ianiro, Experimental Aerodynamics. 2017.

20. Zerihan, J. and Zhang, X., 2001. Aerodynamics of Gurney flaps on a wing in ground effect. AIAA journal, 39(5), pp.772-780.

21. Zhang, Xin and Zerihan, Jonathan (2003) Aerodynamics of a double-element wing in ground effect. AIAA Journal, 41 (6), $1007-1016$.

22. Pavia, G., Varney, M., Passmore, M., and Almond, M., "Three dimensional structure of the unsteady wake of an axisymmetric body," Phys. Fluids 31, 025113 (2019)

\section{Contact Information}

Tom Marsh

Graham Hodgson

g.hodgson@lboro.ac.uk

Andrew Garmory

a.garmory@lboro.ac.uk

Dipesh Patel

d.patel@lboro.ac.uk

\section{Acknowledgments}

The authors would like to thank Mr. Andy Horsley for the technical support provided in preparation for the experiments.

Page 12 of 14

$01 / 14 / 2020$ 


\section{Definitions/Abbreviations}

PIV

Particle Image Velocimetry

RMS

Root Mean Square

Page 13 of 14

$01 / 14 / 2020$ 
Page 14 of 14

$01 / 14 / 2020$ 